\title{
Association between epicardial adipose tissue thickness and coronary heart disease :a meta-analysis
}

\author{
Shuai Yuan ${ }^{1}$ and Da xin Wang ${ }^{1}$ \\ ${ }^{1}$ Yangzhou University Affiliated Northern Jiangsu People's Hospital
}

July 16, 2020

\begin{abstract}
Epicardial fat is the true visceral fat located around the heart, particularly around sub epicardial coronary arteries . Epicardial and intra-abdominal fat derive from brown adipose tissue within embryogenesis. Because of the close anatomical relationship to the heart, and the absence of fascial boundaries, epicardial adipose tissue (EAT) may locally interact and modulate the coronary arteries and myocardium through paracrine or vasocrine secretion of anti-inflammatory and proatherogenic cytokines . Therefore, it is meaningful to explore its connection with CAD.
\end{abstract}

\section{Hosted file}

DOCUMENT.docx available at https://authorea.com/users/342631/articles/470234-associationbetween-epicardial-adipose-tissue-thickness-and-coronary-heart-disease-a-meta-analysis
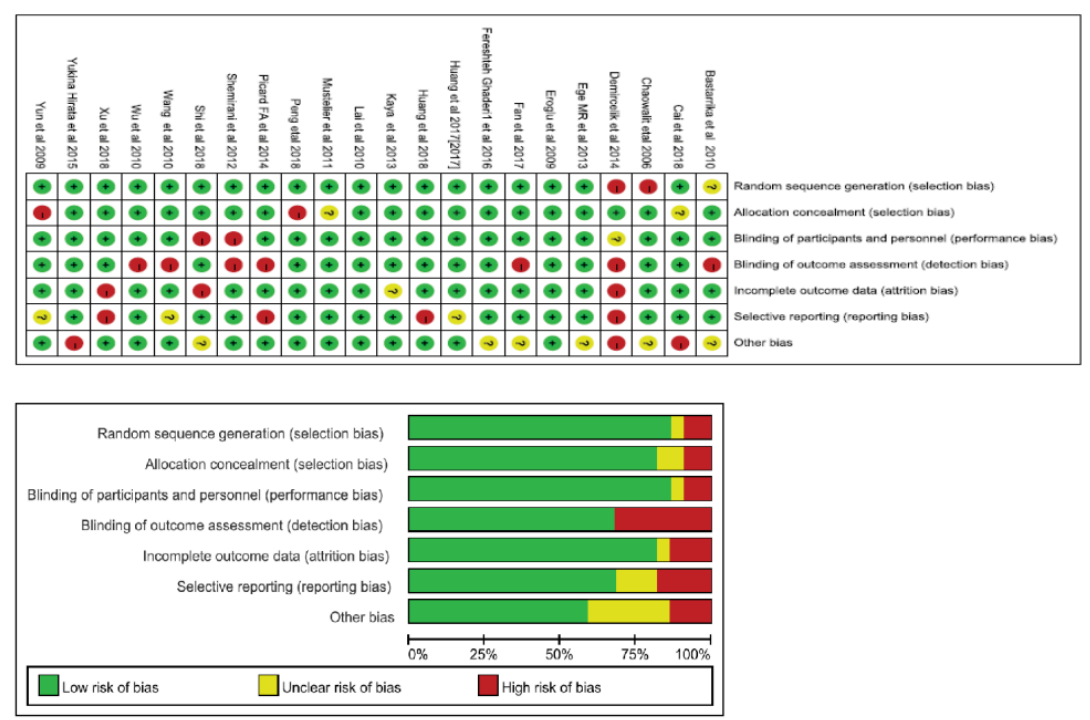

Figure 1: Summary table of publication bias included in the study. 


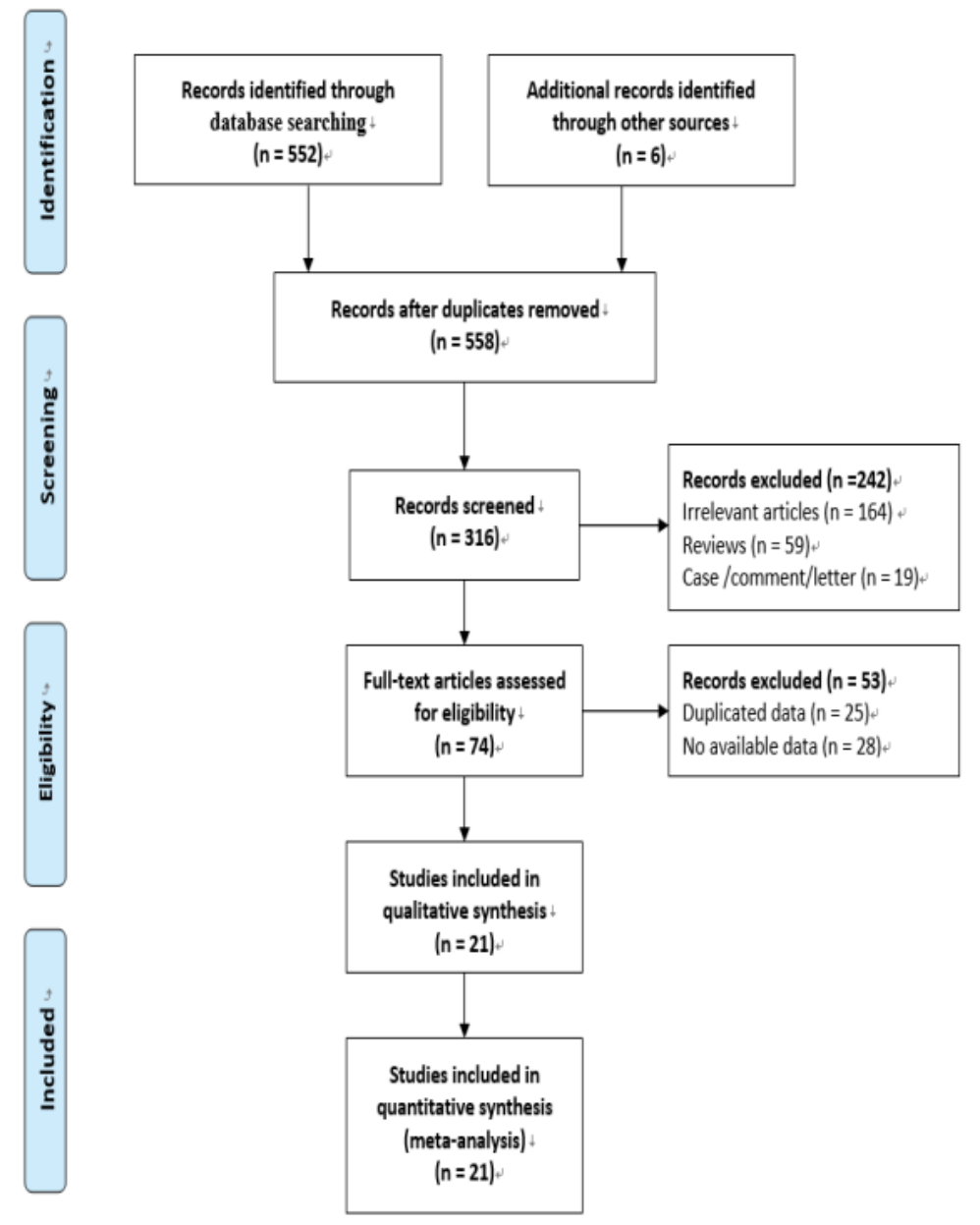

Figure 2: Meta analysis based on PRISMA statement included in the study flow chart.



Figure 3: EAT and CAD (Mean and standard deviation of epicardial adipose thickness (measured by echocardiography, CT) in patients with and without Coronary Artery Disease (CAD) in each study and overall analysis). 


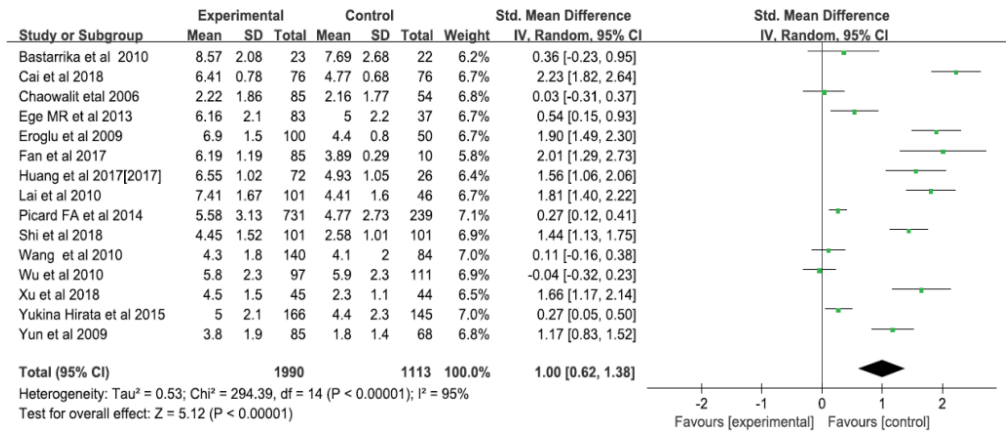

Figure 4: EAT and CAD (Mean and standard deviation of epicardial adipose thickness (measured by echocardiography) in patients with and without Coronary Artery Disease (CAD) in each study and overall analysis).



Figure 5: EAT and CAD (Mean and standard deviation of epicardial adipose thickness (measured by CT) in patients with and without Coronary Artery Disease (CAD) in each study and overall analysis).

\begin{tabular}{|c|c|c|c|c|c|c|}
\hline \multirow[b]{2}{*}{ Included in the study } & \multirow{2}{*}{$\begin{array}{c}\mathrm{N} \\
\text { (total) }\end{array}$} & \multirow{2}{*}{$\begin{array}{c}\text { CAD } \\
n\end{array}$} & \multirow[b]{2}{*}{$\begin{array}{c}\text { EAT Thickness/ } \\
\text { mm }\end{array}$} & \multicolumn{2}{|r|}{ Non-CAD } & \multirow{2}{*}{$\begin{array}{c}\text { Tools to } \\
\text { Measurement }\end{array}$} \\
\hline & & & & $\mathbf{n}$ & EAT Thickness/mm & \\
\hline Yukina Hirata et al [9] & 311 & 166 & $5 \pm 2.1$ & 145 & $4.4 \pm 2.3$ & Echocardiography \\
\hline Fereshteh Ghaderi1 et al [10] & 100 & 59 & $6.9 \pm 3$ & 41 & $3.6 \pm 1.2$ & Computed Tomography \\
\hline Demircelik et al [11] & 89 & 53 & $7.1 \pm 2.7$ & 36 & $3.2 \pm 3.1$ & Computed Tomography \\
\hline Ege MR et al [12] & 120 & 83 & $6.16 \pm 2.1$ & 37 & $5 \pm 2.2$ & Echocardiography \\
\hline Kaya et al [13] & 64 & 34 & $6.43 \pm 0.9$ & 30 & $5.34 \pm 0.78$ & Computed Tomography \\
\hline Shemirani et al [14] & 292 & 171 & $5.4 \pm 1.9$ & 121 & $4.4 \pm 1.8$ & Computed Tomography \\
\hline Mustelier et al [15] & 250 & 185 & $6.6 \pm 2.8$ & 65 & $4.7 \pm 2.3$ & Computed Tomography \\
\hline Lai et al [16] & 147 & 101 & $7.41 \pm 1.67$ & 46 & $4.41 \pm 1.6$ & Echocardiography \\
\hline Wu et al [17] & 208 & 97 & $5.8 \pm 2.3$ & 111 & $5.9 \pm 2.3$ & Echocardiography \\
\hline Bastarrika et al [18] & 45 & 23 & $8.57 \pm 2.08$ & 22 & $7.69 \pm 2.68$ & Echocardiography \\
\hline Wang et al [19] & 224 & 140 & $4.3 \pm 1.8$ & 84 & $4.1 \pm 2$ & Echocardiography \\
\hline Eroglu et al [20] & 150 & 100 & $6.9 \pm 1.5$ & 50 & $4.4 \pm 0.8$ & Echocardiography \\
\hline Yun et al [21] & 153 & 85 & $3.8 \pm 1.9$ & 68 & $1.8 \pm 1.4$ & Echocardiography \\
\hline Picard FA et al [22] & 970 & 731 & $5.58 \pm 3.13$ & 239 & $4.77 \pm 2.73$ & Echocardiography \\
\hline Chaowalit et al [23] & 139 & 85 & $2.22 \pm 1.86$ & 54 & $2.16 \pm 1.77$ & Echocardiography \\
\hline Huang et al [24] & 98 & 72 & $6.55 \pm 1.02$ & 26 & $4.93 \pm 1.05$ & Echocardiography \\
\hline Cai et al [25] & 152 & 76 & $6.41 \pm 0.78$ & 76 & $4.77 \pm 0.68$ & Echocardiography \\
\hline Peng et al [26] & 151 & 81 & $12.21 \pm 2.62$ & 70 & $9.92 \pm 1.37$ & Computed Tomography \\
\hline Xu et al [27] & 89 & 45 & $4.5 \pm 1.5$ & 44 & $2.3 \pm 1.1$ & Echocardiography \\
\hline Shi et al [28] & 202 & 101 & $4.45 \pm 1.52$ & 101 & $2.58 \pm 1.01$ & Echocardiography \\
\hline Fan et al [29] & 95 & 85 & $6.19 \pm 1.19$ & 10 & $3.89 \pm 0.29$ & Echocardiography \\
\hline
\end{tabular}

